\title{
ANAESTHESIA FOR THE PATIENT WITH A COINCIDENTAL GIANT LUNG BULla: A CASE REPORT
}

\author{
Nigel G. CASEby
}

\begin{abstract}
The anaesthetic management of a patient with a coincidental giant lung bulla who underwent lumbar discectomy and laminectomy is described. The specific problems associated with anaesthesia in patients with bullae, such as acute enlargement or rupture of the bullae, are discussed. Precautionary measures which may be taken during anaesthesia include the avoidance of nitrous oxide, the prophylactic use of a double-lumen tube, and the immediate availability of chest drains in the anaesthetizing area. Monitoring during operation may involve bilateral chest auscultation and arterial blood gas analysis.
\end{abstract}

KEY WORDS: ANAESTHESIA, complications; LUNG, giant bulla.

Patients with coincidental giant bullae occasionally present for operations outside the thorax. These patients are at increased risk during anaesthesia from potential complications which may arise from the bullae or underlying lung disease. Specific problems associated with giant bullae include rapid enlargement or rupture of the air spaces. The technique of anaesthesia that most authorities recommend for patients with bullae is one which avoids the use of nitrous oxide' and involves spontaneous ventilation throughout the total procedure. ${ }^{2-4}$ Sometimes a technique of balanced anaesthesia utilizing intermittent positive pressure ventilation (I.P.P.V.) is indicated due to coexisting disease or for operations where neuromuscular blockade is required. There is a danger that I.P.P.V. may result in overinflation of a bulla if it communicates with the airway. The anaesthetic management of an elderly patient with a giant bulla and associated emphysema, who was to be placed in a position which would interfere with spontaneous ventilation, is presented in the following case report.

\section{Case History}

A 70 year old male was scheduled for lumbar discectomy and possible laminectomy. There

Nigel G. Caseby, M.B., Ch.B., F.F.A.R.C.S., F.R.C.P.(C)., Director of the Intensive Care Unit, The General Hospital, Health Sciences Centre, St. John's, Newfoundland. Assistant Professor of Anaesthesia, Memorial University of Newfoundland, St. John's, Newfoundland.

Present Address: Department of Anaesthesia, Toronto General Hospital, 101 College Street, Toronto, Ont., M5G 1 L7. was little in his medical history or physical examination to suggest any major anaesthetic problem. However, a routine chest $x$-ray revealed a giant bulla in the upper part of the right hemithorax (Figure 1). The bulla occupied rather more than one third of the hemithorax, extending throughout the right upper zone and medial part of the right mid-zone. In addition there were diminished lung markings with increaesd radiolucency in both basal regions, particularly the right, indicating emphysema in the lower lobes. There was also old fibrotic disease in the right mid-zone. There had been no radiological change since his last chest film nine months previously. Because of the unexpected radiological findings pulmonary functions tests were done. They showed a normal vital capacity of 3.61 and a mild degree of irreversible airways obstruction (miclmaximal expiratory flow rate of 1.41 and a one second forced expiratory volume to vital capacity ratio of 65 per cent). The functional residual capacity (FRC) and residual volume, measured by a helium dilution method, were below normal at 89 and 85 per cent respectively of predicted values, suggesting that the bulla was poorly ventilated. Diffusion tests were normal. The tidal volume of 0.6341 was larger than predicted. Arterial carbon dioxide tension $\left(\mathrm{Pa}_{\mathrm{CO}_{2}}\right)$, measured by a rebreathing technique, was $5.72 \mathrm{kPa}$ $(43 \mathrm{mmHg}$ ). Arterial blood gas analysis was not done as the patient was neither cyanosed nor in any respiratory distress, and the $\mathrm{Pa}_{\mathrm{CO}_{2}}$ was already known to be normal.

The surgeon indicated a definite preference for the patient to be anaesthetized in the prone position with flexion of the lumbar spine. Epidural or spinal anaesthesia were considered as

Canad. Anaesth. Soc. J., vol. 28, no. 3, May 1981 272 


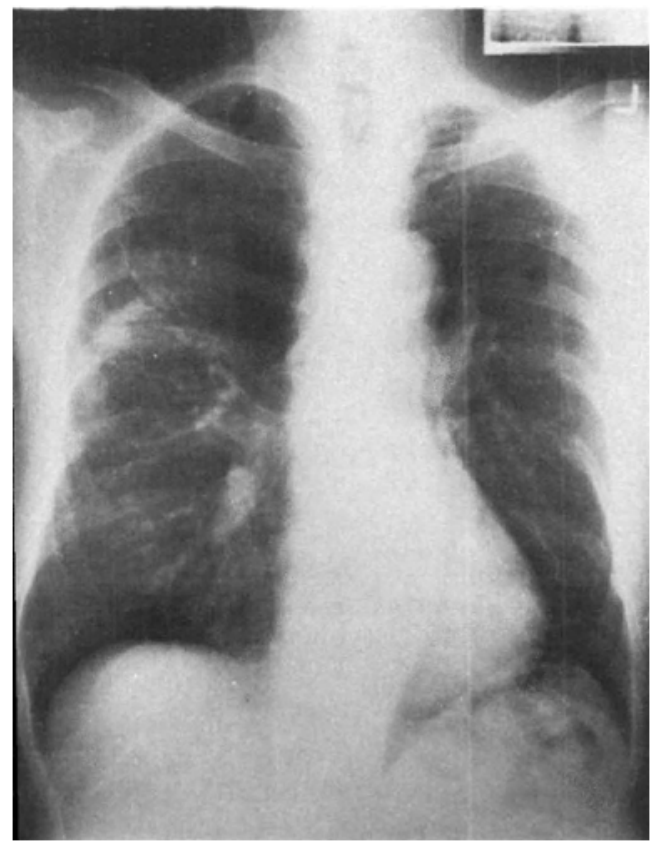

FIGURE 1 The pre-operative chest $x$-ray shows a giant bulla in the right upper and mid zones, occupying rather more than one-third of the right hemithorax. Compression of the adjacent lung is manifest by (a) accentuation of the right paratracheal stripe, and (b) crowding of lung markings infero-lateral to the bulla. There is also increased radiolucency in both lung bases indicating emphysema.

possible anaesthetic techniques but were discounted due to the possibility of haemodynamic instability and/or ventilatory difficulties in the prone position. A technique of general anaesthesia with spontaneous ventilation was also ruled out because of the risk of hypoventilation. A decision was made to utilize general anaesthesia and I.P.P.V. together with certain precautions. These measures included the immediate availability of two chest drain packs in the operating room, the avoidance of nitrous oxide in the inhalational mixture, and the prophylactic insertion of a double-lumen tube at induction of anaesthesia.

Pre-anaesthetic medication with meperidine $100 \mathrm{mg}$ and atropine $0.6 \mathrm{mg}$ was given intramuscularly one hour before the operation. In the operating room continuous electrocardiographic monitoring was started and two stethoscopes were attached to the chest wall posteriorly to allow intermittent monitoring of breath sounds of both lungs. After adequate pre-oxygenation, and with the patient lying supine on a trolley, anaesthesia was induced with thiopentone $250 \mathrm{mg}$ followed by succinylcholine $100 \mathrm{mg}$. The trachea was intubated with a large left-sided Robertshaw double-lumen tube without difficulty. Gentle manual ventilation of the lungs with an airoxygen-enflurane mixture was carried out while the tube was secured. At the first sign of recovery from the depolarising paralysis, d-tubocurarine $30 \mathrm{mg}$ was given and I.P.P.V. was started with an Ohio ventilator through a circle circuit with carbon dioxide absorption. A tidal volume of $600 \mathrm{ml}$ was delivered at a rate of $12 \mathrm{per} \mathrm{min}$. An inspiratory flow rate of $301 / \mathrm{min}$ was used with an inspiratory to expiratory ratio of approximately 1:3. This ventilatory pattern resulted in a peak inspiratory airway pressure of $1.96 \mathrm{kPa}(20 \mathrm{~cm}$ $\mathrm{H}_{2} \mathrm{O}$ ). The patient was then log-rolled into the prone position and placed on logitudinal bolsters on the operating table. Spinal flexion was produced and the abdomen was examined to ensure free movement. Anaesthesia was maintained with enflurane $0.50-1.50$ per cent delivered in an air (four litres/min) and oxygen (one litre/min) mixture. Supplementation of anaesthesia was provided by four doses of fentanyl $50 \mu \mathrm{g}$ given intravenously at approximately half-hourly intervals. An additional $9 \mathrm{mg}$ of d-tubocurarine was administrerd 90 minutes after induction of anaesthesia.

The anaesthetic course was completely uneventful throughout the two and one-half hour operation. The patient remained haemodynamically stable. Peak airway pressure during I.P.P.Y.

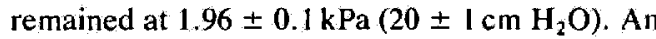
arterial blood gas determination 30 minutes after induction confirmed satisfactory ventilation and oxygenation, $\mathrm{cH}^{+} 39 \mathrm{nmol} / \mathrm{l}(\mathrm{pH} \mathrm{7.41}), \mathrm{Pa}_{\mathrm{CO}}$ $5.45 \mathrm{kPa}(41 \mathrm{mmHg}), \mathrm{HCO}_{3} 26 \mathrm{~m} \mathrm{~mol} / \mathrm{l}$, and $\mathrm{Pa}_{\mathrm{U}_{2}}$ $17.42 \mathrm{kPa}$ ( $131 \mathrm{mmHg}$ ). A lumbar discectomy and bilateral decompression laminectomy were performed. At the end of the operation the patient was returned to the supine position. The enflurane was discontinued and neostigmine and atropine were administered. Naloxone $0.4 \mathrm{mg}$ was also given. Spontaneous ventilation was quickly resumed and the trachea was extubated. On admission to the recovery room oxygen ( 5 litres/min) was supplied through a plastic mask. An arterial blood sample 10 minutes later showed $\mathrm{cH}^{+} 42 \mathrm{n}$ $\mathrm{mol} / 1$ (pH 7.38) $\mathrm{Pa}_{\mathrm{CO}_{2}} 5.98 \mathrm{kPa}(45 \mathrm{mmHg}), \mathrm{HCO}_{3}$ $26 \mathrm{~m} \mathrm{~mol} / \mathrm{l}$, and $\mathrm{Pa}_{\mathrm{O}_{2}} 22.74 \mathrm{kPa}(171 \mathrm{mmHg}) . A$ chest $x$-ray taken in the recovery room was similar to the pre-operative film except for a small linear atelectatic density at the left base. In the post-operative period the patient developed no pulmonary problem. 


\section{Discussion}

A bulla is an air-containing space within the lung parenchyma of more than one $\mathrm{cm}$ in diameter. ${ }^{5}$ Bullae occur both singly and in multiples, either in otherwise normal lungs or in association with different types of pulmonary lesions, particularly emphysema.$^{6-8}$ In the majority of patients the bullae enlarge progressively, although the rate of enlargement is not predictable and may be extremely slow: ${ }^{9}$ A giant bulla is one which has enlarged greatly: it may be produced by an exaggeration of the mechanisms which give rise to emphysema or it may be the result of a valve mechanism in the bronchial communication which permits air trapping within the bulla. As the bulla expands, surrounding normal lung tissue may be compressed. Giant bullae are commonly found with paraseptal emphysema and in emphysema association with scars, ${ }^{8}$ but they may also occur in association with progressive fibrotic lung disorders. ${ }^{6.8}$ It is well known that giant bullae can develop during or after acute pulmonary infections, particuarly staphylococcal pneumonia. The term pneumatocele has been recommended to describe bullae which occupy one-third or more of a hemithorax, ${ }^{10}$ but to others it defines the abnormal air spaces of staphylococcal pneumonia. The most important complications of bullae include infection, spontaneous pneumothorax, and haemorrhage into a bulla.

The problems associated with anaesthesia for the patient with a giant bulla are two-fold: firstly, the possibility of further enlargement of the bulla occurring under anaesthesia and, secondly, the general problems associated with disease (usually emphysema) in the remaining lung tissue. Rapid enlargement of a bulla, especially one which communicates poorly or not at all with the bronchial tree, can occur under anaesthesia with nitrous oxide due to a difference in the solubilities of nitrous oxide and nitrogen in the blood. ${ }^{1}$ During the initial stages of administration the rate of transfer of nitrous oxide from blood to an air-filled bulla may be 34 times greater than the rate of removal of nitrogen. The increased number of molecules of nitrous oxide in the bulla results in an increase in its volume if it is compliant, or a rise in pressure in a noncompliant air space. Transfer of nitrous oxide into the bulla, at a faster rate than nitrogen removal, continues until there is equilibration between the partial pressure of nitrous oxide in the blood and the bulla. The amount of expansion of the bulla, therefore, depends on the concentra- tion of nitrous oxide in the lungs. In animal studies, the use of 75 per cent nitrous oxide in the presence of an air-space (artificial pneumothorax) resulted in a two-fold increase in gas volume within 10 minutes, whereas virtually no volume change occurred on adminstration of an oxygen-halothane mixture."

In patients with bullae which communicate with airways the use of I.P.P.V. may result in overinflation of the bullae when either a large tidal volume is delivered or insufficient time is allowed for expiration, and air trapping occurs. Acute enlargement of a bulla during I.P.P.V. may occur, regardless of the ventilatory pattern, where a check-valve mechanism exists which allows gas to enter, but not to leave, the bulla.

Whatever the cause of enlargement of a bulla, the effects are the same, namely compression of adjacent lung tissue and the eventual development of a bulla under tension. This build-up of pressure within the bulla may result in a shift of the mediastinum to the opposite side, leading to vena caval kinking and circulatory inadequacy. Alternatively, rupture of the bulla wall may occur with the possible consequences of pulmonary venous gas embolism or release of gas into either the pleural cavity or the interstitial tissues of the lung. Gas in the lung interstitium may dissect back via the hilum to the mediastinum (pneumomediastinum) or it may dissect further either retroperitoneally or upward into the subcutaneous tissues of the neck. ${ }^{12} \mathrm{~A}$ continued leak of gas into the pleural cavity may result in a tension pneumothorax, which has effects similar to but more profound than a bulla under tension.

The presence of any associated lung disease in patients with bullae merits attention. It is generally agreed that the functional disturbance in patients with bullae is determined more by the state of the lungs as a whole than by the effect of an individual bulla. ${ }^{\circ}$ Even large bullae of onethird of one hemithorax may cause few symptoms and little impairment in lung function if they arise in otherwise healthy lungs. ${ }^{6.13}$ In a lung with generalized obstructive airways disease, however, the presence of a large bulla may critically affect the total function, and the problems which may be encountered during anaesthesia are, naturally, greatly increased. As a rule bullae are poorly ventilated as well as poorly perfused and, therefore, do not contribute greatly toward either shunting or dead space ventilation. ${ }^{14,15}$

Regional anaesthesia is the anaesthetic technique of choice for surgery in patients with giant 
bullae. When local anaesthesia is considered inappropriate and general anaesthesia is contemplated, the use of nitrous oxide is contraindicated.' A technique of general anaesthesia in which spontaneous ventilation is maintained throughout is preferred. ${ }^{2-4}$ After intravenous induction the patient is allowed to breathe inhalational agents until he is sufficiently anaesthetized to allow tracheal intubation without muscle relaxant. It is well to remember that induction of anaesthesia with inhalational agents may be prolonged in patients with emphysema, due to an increase in FRC, a decrease in alveolar ventilation, or ventilation-perfusion abnormalities. ${ }^{16}$

Although I.P.P.V. is best avoided in patients with bullae, it is occasionally necessary to employ a technique involving neuromuscular blockade and mechanical ventilation. When I.P.P.V. is used an effort must be made to keep the transpulmonary pressure (T.P.P.) gradient similar to that during awake spontaneous ventilation. This is partly achieved by delivering a tidal volume which is equal to the patient's pre-operative volume because the T.P.P at a given lung volume is the same for both spontaneous and controlled ventilation. ${ }^{17}$ However, it is impossible to ensure that the T.P.P. gradient will remain the same after anaesthesia is induced, because anaesthesia and paralysis affect the mechanical properties of the lung and chest wall, ${ }^{18}$ and FRC may be reduced. ${ }^{19}$ The patient may return, therefore, to a different FRC after induction of anaesthesia, and he may be ventilated on a different part of the pressure-volume curve. These changes may result in an increase in the T.P.P. gradient, which may increase the risk of overinflation and rupture of the bulla if it communicates with the airway.

The pattern of controlled ventilation considered most appropriate for patients with bullae is similar to that used for patients with obstructive airways disease, even in the absence of functional lung disease. The provision of an adequate time for expiration during I.P.P.V. is important if air trapping is to be avoided. Negative endexpiratory pressure is contra-indicated as it invariably produces proximal airway collapse and air trapping. ${ }^{20}$ The use of an expiratory retard, on the other hand, may hold collapsing airways open for longer and thereby reduce air trapping. A slow inspiratory flow rate is preferred as this may reduce peak airway pressures, thus minimizing possible lung barotrauma. Where nitrous oxide is being deliberately withheld, ventilation with an air-oxygen mixture is preferred to pure oxygen, to avoid the possibility of absorption atelectasis. ${ }^{21,22}$ Sufficient oxygen must be provided to compensate for the increased ventilation-perfusion mismatching and intrapulmonary shunting which occur under anaesthesia. ${ }^{23}$ Oxygen and ventilatory requirements are best ascertained by intra-operative arterial blood gas analysis.

Life-threatening complications which may develop under anaesthesia, such as an enlarged bulla under tension or a pneumothorax, may manifest themselves either by changes in respiratory rate and tidal volume during spontaneous ventilation or by an increase in airway pressure during I.P.P.V. Stethoscopes attached to both sides of the chest may aid in detecting a diminution in breath sounds on the affected side. These changes in respiratory parameters may be accompanied by cyanosis, tachycardia and/or hypotension. When time permits, as in the case of a pneumothorax, an intra-operative chest $x$-ray may help in reaching a definitive diagnosis and taking appropriate action. ${ }^{24}$ On the other hand, when uncontrollable respiratory difficulty occurs under anaesthesia, with cardiovascular changes suggestive of a tension situation, prompt action is required. In such circumstances the side of the chest in which the bulla is located must be decompressed by a tube inserted through a stab wound. If no immediate improvement follows, a chest drain should be placed in the opposite side. After release of the gas under tension the chest drain is attached to underwater seal drainage and suction is applied to allow the lung to re-expand. Surgery and anaesthesia must be terminated as soon as possible after the development of complications, with a return to spontaneous ventilation and continued decompression of the pleural cavity. Respiratory problems may develop at any stage of anaesthesia, but are particularly likely to occur at induction of anaesthesia. Therefore it is best, before proceeding with anaesthesia, to ensure that chest drains and instruments are available and that the surgeon is present.

The formation of a broncho-pleural fistula is a complication which may follow insertion of an emergency chest drain. Sufficient loss of ventilating gas may occur through the fistula to cause inadequate pulmonary ventilation, especially where I.P.P.V. is used. In this situation isolation of the injured lung with a double-lumen tube is indicated and anaesthesia is continued with one lung ventilation and increased oxygen concentration until the operation can be terminated. The passage of the double-lumen tube is best done under non-urgent conditions and, therefore, it is 
inserted as a prophylactic measure at induction of anaesthesia. At the end of the operation a trial of spontaneous ventilation with both lungs is undertaken. Where the leak from the fistula continues to be large and the patient develops ventilatory failure, corrective surgery is indicated. A thoracotomy is done and surgical repair of the fistula is carried out under one lung anaesthesia.

In the present case the bulla occupied more than one-third of the hemithorax and it had not changed in size during the nine months before operation. Pulmonary function testing detected only a mild degree of airway obstruction. Despite the giant bulla and some emphysematous changes in his lung bases, the patient had no respiratory symptoms. His generalized lung disease obviously posed little problem for general anaesthesia, but he was at risk from possible complications of the giant bulla. A technique of balanced anaesthesia with I.P.P.V. was employed for his operation without incident. Anaesthesia was conducted with confidence due to the adoption of special measures to avoid and correct potential complications.

\section{REFERENCES}

1. Munson, E.S. Transfer of nitrous oxide into body air cavities. Br. J. Anaesth. 46: 202 (1974).

2. GRAY, T.C. \& EDWARDS, F.R. The anaesthetic problems associated with giant tension cysts of the lung. Thorax 3: 237 (1948).

3. Brown, A.l.P. Anaesthesia for the respiratory cripple. Proc. R. Soc. Med. 59: 522 (1966).

4. Skivington, M.A. Respiratory Diseases. In, Anaesthesia and Uncommon Diseases: Pathophysiologic and Clinical Correlations. (ed.) Katz, J. \& Kadis, L.B. Toronto: Saunders, p. 176 (1973).

5. A report on the conclusions of a CIBA guest symposium. Terminology, definitions, and classification of chronic pulmonary emphysema and related conditions. Thorax 14:286 (1959).

6. Ogilvie, C. \& Catterall, M. Patterns of disturbed lung function in patients with emphysematous bullae. Thorax 14: 216 (1959).

7. WELCH, M.H. Variants of emphysema and miscellancous disorders of airways. In, Pulmonary Medicine (ed.) Guenter, C.A. and Welch, M.H. Toronto: Lippincott Co., p. 650 (1977).

8. Crofton, J. and Douglas, A. (ed.) Respiratory Diseases. 2nd ed. Oxford: Blackwell Scientific Publications, p. 350 (1975).

9. Boushy, S.F., Kohen, R., Billig, D.M. \& HeI-
MAN, M.J. Bullous emphysema: clinical roentgenologic and physiologic study of 49 patients. Dis. Chest 54: 327 (1968).

10. Fraser, R.G. \& PARÉ, J.A.P. (ed.) Diagnosis of Diseases of the Chest. 2nd ed. Toronto: Saunders p. 1421 (1979).

11. Eger, E.I. II \& Saidman, L.J. Hazards of nitrous oxide anaesthesia in bowel obstruction and pneumothorax. Anesthesiology 26: 61 (1965).

12. MaCKLIN, C.G. Transport of air along sheaths of pulmonic blood vessels from alveoli to mediastinum. Clinical implications. Arch. Int. Med. 64: 913 (1939).

13. WoO-Ming, M., CAPEl, L.H. \& Belcher, J.R. The results of surgical treatment of large air cysis of the lung. Br. J. Dis. Chest 57: 79 (1963).

14. Pride, N.B., Barter, C.E. \& Hugh-Jones, P. The ventilation of bullae and the effect of their removal on thoracic gas volumes and tests of overall pulmonary function. Am. Rev. Respirat. Dis. 107: 83 (1973).

15. Pride, N.B., Hugh-Jones, P., O'Brien, E.N. \& SMITH, L.A. Changes in lung function following the surgical treatment of bullous emphysema. Quart. J. Med. 39: 49 (1970).

16. EGER, E.I. II. Uptake, distribution and elimination of inhaled anaesthetics. In, Scientific Foundations of Anaesthesia. (ed.) Scurr, C. \& Feldman, \$. London: Heinemann, p. 444 (1974).

17. Sykes, M.K., MCNicol, M.W. \& Campbeli, E.J.M. Respiratory Failure, 2nd ed. London: Blackwell Scientific Publication, p. 200 (1976).

18. Westbrook, P.R., StubBs, S.E., Sessler, A.D., REHDER, K.\& HyATT, R.E. Effects of anaesthesia and muscle paralysis on respiratory mechanics in normal man. J. Appl. Physiol. 34: 81 (1973).

19. Hewlett, A.M., Hulands, G.H., NunN, J.F. \& MiLledge, J.S. Functional residual capacity duting anaesthesia. III: Artificial ventilation. Br. I. Anaesth. 46: 495 (1974).

20. Galloon, S. \& Rosen, N. Changes in airway resistance and alveolar trapping with positivenegative ventilation. Anaesthesia 20: 429 (1965).

2l Potgreter, S.V. Atelectasis: its evolution during upper urinary tract surgery. Br. J. Anaesth. $31: 472$ (1959).

22. Nunn, J.F., Williams, I.P., Jones, J.G., HewLETT, A.M., Hulands, G.H. \& MinTy, B.D. Detection and reversal of pulmonary absorption collapse. Br. J. Anaesth. 50:91 (1978).

23. Dueck, R., Rathbun, M., Clausen, J. \& WAGNER, P.D. Altered distribution of pulmonary ventilation and blood flow following induction of inhalation anaesthesia. Anesthesiology 52: 113 (1980).

24. Christian, M.S., Munson, E.S. \& Hamilton, W.K. Pneumothorax following induction of anaesthesia. J.A.M.A. 209: 1710 (1969).

RÉSUMÉ

Cette publication rapporil: la conduite de l'anesthésie chez un malade porteur d'une bulle géante d'emphysème et ayant subi une discoïdectomie lombaire. Les problèmes spécifiques reliés à l'anesthésie chez les porteurs de bulles d'emphysème, notamment la dilatation et la rupture des bulles, $y$ sont discutés. Comme mesures préventives on a recommandé d'éviter le protoxyde d'azote, d'employer des tubes à double lumière et de garder à portée de la main des tubes à drainage thoracique. La surveillance per-opératoire devrait inclure l'auscultation des deux plages pulmonaires et l'analyse des gaz artériels. 